MS. KATRINA HAUSCHILDT (Orcid ID : 0000-0002-1000-2275)

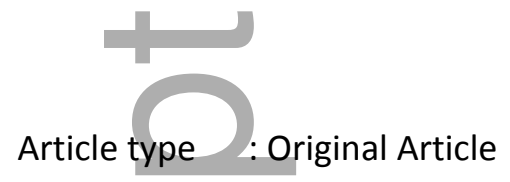

$\square$

(

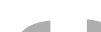

\title{
Reinforcing Medical Authority: Clinical Ethics Consultation and the Resolution of Conflicts in Treatment Decisions
}

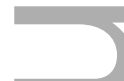

Katrina Hauschildt ${ }^{1}$ and Raymond De Vries ${ }^{2}$

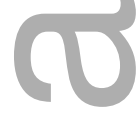

${ }^{1}$ Department of Sociology, University of Michigan, Michigan, USA

${ }^{2}$ Center for Bioethics and Social Sciences in Medicine, University of Michigan Medical School, Michigan, USA

KEY WORDS: clinical ethics; physician authority; United States; patient autonomy; doctorpatient communication; medical decision-making; bioethics

\section{ABSTRACT}

Despite substantial efforts in the past fifteen years to professionalise the field of clinical ethics consultation, sociologists have not reexamined past hypotheses about the role of such services in medical decision-making and their effect on physician authority. In relation to those hypotheses, we explore two questions: 1) What kinds of issues does ethics consultation resolve? and 2) what

This is the author manuscript accepted for publication and has undergone full peer review but has not been through the copyediting, typesetting, pagination and proofreading process, which may lead to differences between this version and the Version of Record. Please cite this article as doi: $10.1111 / 1467-9566.13003$

This article is protected by copyright. All rights reserved 
it the nature of the resolution afforded by these consults? We examined ethics consultation records created between 2011 and mid-2015 at a large tertiary care US hospital and found that in most cases, the problems addressed are not novel ethical dilemmas as classically conceived, but are instead disagreements between clinicians and patients or their surrogates about treatment. The resolution offered by a typical ethics consultation involves strategies to improve communication rather than the parsing of ethical obligations. In cases where disagreements persist, the proposed solution is most often based on technical clinical judgements, reinforcing the role of physician authority in patient care and the ethical decisions made about that care.

\section{INTRODUCTION}

Scholars from several disciplines have helped to chronicle the rise of bioethics and the professionalising efforts of its practitioners (Evans 2012; Jonsen 1998; Kohlen 2011; Rothman 1991; De Vries, Dingwall, and Orfali 2009). The sociological literature documents the rise of clinical ethics and the creation of occupational space for them within medical care (Bosk 2008; Evans 2012) and explores the practice of medical ethics by physicians (Anspach 1997; Chambliss 1996; Zussman 1992), but the practical, everyday work of clinical ethicists has been neglected (Orfali 2018). Further, overall changes in medical delivery, such as the rise of the patient-as-consumer and patient-centered medicine (Churchill 1999; Conrad and Leiter 2004; Tham and Letendre 2014) suggest the role of clinical ethicists in the medical decision-making process should be re-explored. Are clinical ethicists "strangers at the bedside" (Rothman 1991; White et al.2018)? Do they pose a threat to physician authority?

In this paper, we explore the practice of ethics consultation. In our study, we adopt a "sociology of bioethics" approach (De Vries 2017). We are not seeking to solve or analyse problems brought to us by bioethicists, rather we are seeking to better understand the place of bioethics in, and its impact on, the practice of medicine and the life sciences. In particular, we examine four and half years of clinical ethics consultation records from a large academic hospital in order to learn how ethics consultation influences physician authority in decision-making. To that end, we consider two questions: 1) What are the issues that ethics consultation is called upon to resolve? and 2) what is the nature of the resolution provided? 


\section{BACKGROUND}

\section{Bioethics and Medical Authority}

Numerous historical accounts refer to the mid- $20^{\text {th }}$ century as the "golden age of doctoring", a time when physicians enjoyed substantial prestige, autonomy, and in their interactions with patients, authority over how medical information was shared and how decisions about treatment were made (McKinlay and Marceau 2013). However, starting in the 1970s, some scholars contend physicians began to experience economic and political challenges to their professional autonomy, which foretold possible limits to their authority in decision-making (Starr 1982). After the passage of Medicare, which established the federal government as a primary payer for medical care and hospital services, a series of reforms were proposed, and some enacted, to payment structures, which limited the reimbursements hospitals would receive for particular diagnostic categories. These reduced reimbursements provoked hospitals and other health care organisations to increase oversight of the treatments and care physicians provided, although while physicians were increasingly expected to meet standards of care, physicians (or at least a subset of elite physicians) also remained the primary creators of these practice standards (Freidson 1988; Timmermans and Oh 2010). Still, other mechanisms that arose in this time period have arguably proved to be greater challenges to physician's authority over medical decision-making, including the rise of bioethics.

Many scholars believe that bioethics emerged as the result of a series of events that posed critical questions about the role of medicine and scientific research, coupled with a widespread perception that doctors and scientists were, in response to these questions, resistant to outside accountability (Fox and Swazey 2008; Jonsen 1998; Rothman 1991; De Vries, Dingwall, and Orfali 2009). The cultural context is believed to have played a role as well (Rothman 1991; Zussman 1992); bioethics appeared in the late 1960s, along with a number of social movements that were challenging the authority of institutions and demanding rights for individuals (Rothman 1991; De Vries and Conrad 1998). Bioethicists billed themselves as an answer to the legitimacy challenges facing science and medicine and as experts who could, as outsiders, advise scientists and doctors and establish policies for ethical research and treatment (Evans 2012; White et al. 2018). 
Indeed, in the arena of clinical care, bioethicists have been seemingly quite successful in claiming jurisdiction. Nearly all US hospitals offer some form of clinical ethics consultation, in part because the Joint Commission (JCAHO) requires hospitals to establish a mechanism for resolving clinical ethics questions in order to be accredited (Evans 2012; Fox, Myers, and Pearlman 2007; Joint Commission on Accreditation of Healthcare Organization 2007).

But presence does not imply power. The social location of clinical ethics consultation services suggests that such services may not be well positioned to challenge medical authority. Not only are clinical ethicists typically housed within the institutions they "watch over" (White et al. 2018), but most consultants are "part-time" bioethicists who have their primary appointments elsewhere (Evans 2012). In their survey of those performing clinical ethics consultation, Fox and colleagues (2007) found that more than $75 \%$ were hospital clinicians of some kind. Unlike bioethicists whose primary appointments are in departments of bioethics or philosophy, the professionals providing clinical ethics consultation are primarily doctors, nurses, social workers, and chaplains, whose day-to-day work is more often providing treatment and care rather than commenting on it (Fox et al. 2007).

In order to understand the work of clinical ethicists and the impact of their work on physician authority, sociologists must examine the work of ethics committees and ethics consultants (Orfali 2018). Some scholars have asserted that bioethicists in general, and those performing clinical ethics consultation in particular, are unlikely to raise concerns that contradict the interests of medicine (Bosk 1999; Churchill 1999; Evans 2012), but these claims have yet to be supported by research.

\section{Institutionalisation and the Case for Reexamination}

Sociological analysis of the types of issues that present for ethics consultation, and the types of strategies ethics consultants use to resolve conflicts, will enrich our understanding way of the medical decisions are made and changes in the decision-making process. Importantly, readdressing ethics consultation in the context of substantial institutionalisation efforts over the past few decades will illuminate answers to earlier questions and hypotheses: Do ethics committees "provide a forum for resolving conflicts in which both sides can invoke strong ethical principles?" (Rothman 1991, p.255) Do "ethicists "convert technical issues into moral ones?" (Zussman 1992, p.11) 
Ethics consultants have undeniably found their place in the health care market place. There have been substantial efforts to professionalise the work of clinical ethics consultation, including the development and revision of core competencies (Tarzian et al 2013), the creation of standardised tools for evaluating the quality of individual ethics consultations (Pearlman et al. 2016) and the establishment of formal certification processes for ethics consultants (Fins et al. 2016). These processes have demanded substantial documentation of the processes of ethics consultation and the nature of ethicists' advisements to clinicians. These efforts may serve to limit physician discretion or they may simply reinforce physician authority (Bosk 1999; Churchill 1999; Evans 2012; Keirns and De Vries 2009). Examination of the records of ethics consultation offers insight into the logics ethics consultants use to resolve conflicts and the implications of these processes for medical decision-making.

In addition, examination of the types of issues addressed in ethics consultations can illuminate new challenges facing health care systems. In the US there is increasing attention to the definition of appropriate end-of-life care and the costs of, and access to, that care (Byhoff et al. 2016; Livne 2014). It is no surprise then that recent research suggests end-of-life issues are prevalent in ethics consultation. The strategies deployed by ethics consultants to resolve these disagreements are particularly salient among an aging US population and merit further investigation. Consequently, both the drivers of ethics consultation, and the types of strategies ethics consultants use to resolve conflicts, are important to understanding potential changes in medical decision-making as well as how major social issues are approached by clinical ethics consultation.

\section{SETTING AND METHODS}

\section{Clinical Ethics Consultation at Southwest Hospital}

Southwest Hospital ${ }^{\mathrm{i}}$ is a large tertiary care hospital with an associated medical school and nearly 50,000 admissions each year. The ethics committee at Southwest Hospital provides access to the ethics consultation service 24 hours a day. Two members of the committee are "on call" for two week periods and handle any requests for consultations during that time. Patients, their families, or members of the clinical team can request a consultation. An effort is made to assign both a clinician and non-clinician (i.e., a philosopher, lawyer, chaplain, etc.) to each consult. However, 
during the period studied here, Southwest Hospital had an entirely volunteer ethics committee, and it was not always possible to make sure consultations were conducted by both a clinician and non-clinician, or even by two consultants.

When a consult is requested, the consultant(s) on call meet(s) with the treating physicians and other members of the clinical team to obtain information about the patient's condition and the issues or concerns that provoked the consult request; they also generally meet with the patient and/or their family members. After conducting the consultation, but prior to providing their recommendation(s) to the involved parties, a description of the case and the recommendation(s) is made available to other members of the ethics committee so they can comment on and discuss the case. These case records and communications are retained by the ethics committee and referred to below as consultation records.

\section{Methods}

The consultation records provide written documentation of how consultants perform consultations and craft recommendations. All consultation records created between January 2011 and April $2015(\mathrm{n}=156)$ were reviewed. Consults were first read through in their entirety. During this read-through, any identifying information was removed from the records ${ }^{\mathrm{iii}}$ and key descriptive details about each consult were identified, including who conducted the consultation, the primary issue identified by the consultant(s), who requested the consult, the time spent on the consult, and where available, the patient's age, gender, and race/ethnicity ${ }^{\text {iv }}$. Further, notes were taken during this initial read-through about emerging patterns and themes and used to develop a set of broad categories about the types of cases and the strategies used for resolutions. Within these categories, both open and directed coding were then used to create detailed codes (Emerson et al. 2011). This process was iterative; a random consult order was generated, and the first 50 consultations were coded to develop a detailed codebook, and then all consultations were coded using this codebook. The methodology and materials used for this study were evaluated by the authors' Institutional Review Board and determined to be exempt from formal review.

\section{RESULTS}

\section{Case Descriptives}


Table 1 provides key descriptive details about the consultations included in our analysis. In our sample, almost half of all consults were recorded by a single consultant $(n=66)$ and in all but five of these cases, the consultant was a physician. Occasionally, a consult would be performed by more than two consultants $(n=26)$; this typically occurred when medical students participated in the consult process. Time spent on the consultation was recorded for approximately $75 \%$ of consultations and ranged in length from 30 minutes to 7 hours. More than half of consultations for which duration was reported lasted between 2 and 3.5 hours. Where possible, we also recorded patient demographic information. Slightly more consultations were conducted with female patients oyer male patients. Additionally, cases involved patients across a wide range of ages, from 18 to 102 years old. Information about a patient's race, education, income, religion, and insurance status were not often recorded.

\section{What Drives Requests for Ethics Consultation}

In identifying the types of cases that drive requests for ethics consultation, we sought to better understand the nature of the ethical dilemmas presented. Table 2 provides a summary of case types. Notably, the most common driver of ethics consults (63\% of cases) were disagreements or expected disagreements between clinicians and the legal decision-maker (the patients or surrogates) about treatment. A minority of cases were characterised by disagreements between other parties: $3 \%$ of consults involved conflicts amongst staff members, and $4 \%$ involved conflicts amongst family members or between patients and their family members. Cases that were not characterised by disagreements included approximately $15 \%$ of cases focused on identifying a surrogate decision maker for a patient who could not make decisions, and another $15 \%$ which were characterised by novel ethical questions in which the moral choice was unclear to the parties involved. These latter cases often produced novel ethical discussions and recommendations specific to that case. Appendix A provides examples of each of these case types.

\section{Identifying the Primary Issue: How Disagreements are Framed}

Of the $63 \%$ of cases driven by disagreements between clinicians and patients or their surrogates, approximately one-third involved instances in which doctors wanted to perform a treatment and the patient or their surrogate were refusing the treatment. Cases where patients refuse treatment 
recommended by the clinician(s) were often characterised by the ethics consultant as questions of competence/capacity.

Case 191 Summary: “... As early as four years ago, [the patient] has expressed a belief in divine healing and the expectation that God will bring about a healing event such that his LVAD [left ventricular assist device] could be explanted. To this end, he has refused to consider transplant... he has become more insistent that his LVAD be removed and expresses the belief that God will heal his heart and allow him to survive. This is in the face of clinical evidence that all indicates that patient will not survive for long (minutes/hours) without his LVAD in place."

Thus, the key question posed was whether the patient is "able" to refuse care. In many instances, patient's decision-making abilities, not to mention their health literacy levels, were complex, but questions of capacity were presented as binary with respect to specific treatment decisions. Patients may have been considered to have capacity to make simpler decisions while they lacked capacity to refuse other more complex interventions.

Case 136 Summary: "Decisional capacity is decision-specific, that is, it varies according to the complexity and seriousness of the decision at hand: more complex and more weighty decisions require a greater degree of decisional capacity than less complex and less serious ones."

The other two-thirds of disagreements between clinicians and patients or their surrogates were instances in which doctors wanted to withhold treatment of some kind, and patients or their surrogates wanted said treatment.

Case 120 Summary: "[The patient's] family remains firm in their wish that patient remain a FULL CODE with the expressed hope that this will prolong her life. Given the irreversible nature of her underlying disease(s), the primary team feels the actions involved in a cardiopulmonary resuscitation (chest compressions, shocks, etc.) would provide little to no medical benefit while inflicting significant harm."

Cases where physicians would like to withhold treatment that patients or their surrogates want were largely categorised as futility or end-of-life issues by ethics consultants, and the key question was whether the requested treatment is medically appropriate or futile. The depiction of 
cases as primarily questions of decision-making capacity/competence ${ }^{\mathrm{v}}$ or futility framed the evidence and opinions that were used to evaluate the question, with an emphasis on technical clinical judgements. Determinations of decision-making capacity and futility are both classified as medical judgements.

\section{Shaping the Resolution: Strategies and Judgements}

While it might be expected that much of what the ethics consultant does is engage philosophical deliberation and debate, many recommendations focus on process and communication strategies. Ethics consultants generally sought to resolve consults with these strategies first, progressing to lengthier ethical reasoning and philosophy when disagreements persisted after processes and communication were addressed. We conceptualize process and communication strategies as those that do not appeal to ethical principles or reasoning but rather seek to establish clinical information, inform those involved of administrative policies, and improve communication between physicians and patients/decision-makers. While following policies and communication skills are indeed part of good medical practice, drawing on Bosk's (2003) distinction between "technical" and "normative" medical errors, we find that process and communication issues addressed in ethics consultation are navigated as technical aspects of care provision, rather than as normative lapses.

\section{Process Strategies}

In many cases, ethics recommendations proceeded through a series of steps. First, the medical facts of the case were assessed. When clinical ambiguity exists, recommendations often suggested deferring decision making until more clinical knowledge was gained.

Case 144 Recommendations: "Once the irreversibility of her condition is better delineated, the clinical service is thus obligated to honor the patient's wishes ... Of course, in the context of an improving neurological exam, additional time in order to determine how much further she will improve is certainly warranted."

In cases where there was ambiguity around who should make decisions for an incapacitated patient, ethics consultants helped clinicians identify the surrogate of highest priority (as defined by law) or encouraged clinicians to pursue formal guardianship if needed.

Case 143 Summary: "In the absence of documented advance directives or an established 
DPOA, [the patient's] daughter is the surrogate of highest priority and is thus tasked with medical decision-making."

Establishing a process for resolving clinical and administrative ambiguity, with a focus on clinical information and legal/administrative policies, provided resolution to some cases. This is not to say the issues presented were not ethical in nature. Rather, in these cases, the resolution relied less on appeals to morality and instead called on processes characterised by clinical and administrative judgements, like obtaining clearer diagnostic details, identifying the appropriate surrogate according to the law, or referring to hospital policies.

\section{Communication Strategies}

In cases where disagreements about treatment persisted - even though they were clinically straightforward and there was agreement about the appropriate decision-maker recommendations revolved around communication strategies. For example, an inability to regularly reach surrogate decision-makers provoked ethics consults, as was the case below for patient who needed to be discharged to an extended care facility.

Case 233 Summary: "[The sister's] level of unresponsiveness over the course of a week and a half, while unhelpful to the team, does not appear to have reached the threshold required to be seen as abandoning her duties as [her brother's] Durable Power of Attorney (DPOA)."

In other cases, different prognoses, often communicated to patients/their surrogates by different rotating medical staff, or disagreements between different clinicians, led to disagreements between patients and their current providers about treatment.

Case 149 Summary: "Issues regarding prognostication have also been problematic. [The family] reports that last summer, they were told that she would likely die imminently. Again last week, the son reports that he was told that his mother would likely not survive through the night."

Case 221 Summary: "There appears to be some distrust of the both the motivations of the medical team and the interpretation of [the patient's] condition. This may stem from a lack of full understanding of the medical complexities involved in this case, but also appears to be in part a result of receiving conflicting messages from the various care 
providers."

In some instances, simple clarifications about prognosis or a patient's statements resolved disagreement.

Case 217 Summary: "After discussing [the doctor's] concerns, and discussing potential outcomes of the surgery, the patient clarified that she would "of course" be willing to undergo dialysis if necessary... The patient expressed that she was merely trying to convey to the medical team that she would like all possible measures taken to salvage her transplant... Given the clarification of statements on the part of the patient and her sister... there are no current active ethical issues."

In other cases, consultants recommended clinicians discuss and arrive at a consensus for treatment options prior to conversations with patients.

Case 189 Recommendations: “... the [treating] service and nursing staff [need to] set up clear expectations surrounding this issue and work together to solve conflicts prior to discussions with the patient."

Finally, efforts to improve communication overall were also conducive to arriving at a consensus for treatment plans.

Case 171 Summary: "We arrived at a consensus to maintain the current level of care, and to determine if she makes significant progress/improvement over the coming days. The family is comfortable with this plan. All parties recognised the need to communicate more openly and attempt to build further rapport and trust."

Indeed, in more than half of all cases (58\%) communication issues were mentioned or addressed. In many instances recommendations were made to have a meeting to clarify details and explain prognoses to patients or their surrogates and solicit their goals for care.

Case 161 Recommendations: "We agree that the best approach toward approaching withdrawal of care in this case is to continue to address the families concerns, inform them of the patient's prognosis based upon all past and recent information, and facilitate their understanding of what is the most appropriate course. We would recommend getting all members of the care team together... for a sit-down meeting to discuss his case."

This article is protected by copyright. All rights reserved 
Conversations about patient's goals for care focused on identifying "appropriate goals of care", such as returning home or relieving symptoms, rather than asking for patient's or surrogate's preferences about specific treatments. These conversations offered more latitude to clinicians in making some treatment decisions and provided a frame for identifying treatments that, based on clinical judgement, accorded with the patient's wishes.

Case 255 Summary: "I advised [the physician] to discuss goals, not processes of care with the son, and try to help him form realistic goals/expectations... Once the son is able to articulate goals of medical care, the medical team should decide what interventions might be able to achieve those goals."

Many recommendations focused on strategies for facilitating consensus between clinicians and patients and/or their family members. Ethics consultants recommend the use of "expert communicators", particularly palliative care clinicians, for difficult conversations and in getting patients/surrogates to transition to goals of care more in-line with the clinician's views.

Case 102 Discussion: “... Have they considered palliative care consultation to more clearly define goals of care in the setting of incurable cancer which is likely to progress regardless of chemo administered?"

Case 221 Discussion: "...In this case, isn't emphasising that "palliative care should not be considered giving up" sort of disingenuous or at least in need of clarification? Clearly [the family] mean "giving up on the prior goals of treatment" which seems like a fair and accurate description. Clearly you mean that palliative care should not be viewed as "giving up on caring for the patient"..."

Palliative care clinicians were perceived as "expert communicators", particularly in facilitating the acceptance of poor prognoses and directing patients/surrogates to focus on 'attainable' goals.

Case 175 Recommendations: “...[The] primary team can work with [the] family to define and achieve more realistic goals of care... Palliative care and Ethics may be helpful in framing these goals of care discussions."

Strategies for explaining prognosis to patients, identifying patient's goals of care, and involving expert communicators were often successful in diffusing conflicts or disagreements and 
achieving consensus around treatment, without the need for explicit ethical judgements about which treatment course to pursue.

\section{$\underline{\text { Patient Autonomy and Clinical Judgement }}$}

Finally, when process and communication strategies had been deployed and there was still disagreement between patients/families and clinicians about treatment options, there was generally both an implicit and explicit focus on clinical judgements. Referrals to clinical judgements were defined in relation to patient autonomy. While ethics consultants often referred to patient autonomy, they also often discussed the limits of that autonomy. In cases that were depicted as capacity/competency issues, the summaries described how the statements and desires of patients who lacked decision-making capacity were not expressions of their autonomous preferences and therefore need not be respected under the guise of patient autonomy.

Case 154 Summary: "The goal in treating someone who refuses intervention is to restore them to a state where they have decisional capacity and can fully express their autonomy. In emergency situations, MDs may perform life-prolonging interventions - despite protest-under the aegis of "presumed consent"... You cannot be certain that you are respecting the "true wishes" of a patient refusing care who lacks decision-making capacity."

Even when patients had capacity and had articulated their decisions well, it was often considered appropriate to revisit the issue with the hopes of changing their minds.

Case 146 Recommendations: "If the patient is found to have decision-making capacity then her decision should be respected and the patient's informed refusal should be documented in her medical records. This does not mean that the team cannot attempt respectful persuasion."

Regardless of these questions, however, whether patient's expressions were considered valid, autonomous preferences hinges on the clinical determination of decision-making capacity, made by a clinician.

Similarly, cases portrayed as futile provoked discussions centered around the limits of patient autonomy in relation to physician's clinical expertise. 
Case 178 Summary: "1. While there is broad consensus in the bioethical literature regarding the principle of patient (or surrogate) autonomy, this does not extend to the request for care that, in the opinion of the medical team, is more likely to cause harm than benefit.

In end-of-life cases, a strong effort was made to encourage patients or their families to "accept" that the patient was dying and assent to less aggressive care. If these methods failed, the ethics committee often referred to the institution's futility policy.

Case 120 Summary: "Every effort should be made to reconcile gaps communication and understanding during this difficult time for the patient and family. When such a reconciliation is not possible, the primary team's primary responsibility is to provide appropriate medical care to the patient and again, medical providers are under no obligation to provide care they deem medically inappropriate or futile."

Even when the formal guidelines for futility were not met, ethics consultants articulated a rationale for physicians to refuse to provide treatment as a "right to not practice bad medicine" or because a treatment would not address the patient's underlying illness.

Case 179 Summary: "According to the orthopedic surgeon, the non-operative and operative management have equivalent outcomes in terms of healing, pain, and function. Given the high risk of death the primary surgeon was not interested in pursuing operative management... The patient stated that she was willing to have surgery despite the risk of death because the potentially more rapid rehabilitation course would be worth the risk... The medical or surgical team is not obligated to provide any therapy that they believe will do more harm than good."

Like questions of decision-making capacity, futility was framed as a medical judgement and was described as the "purview of the patient's medical providers". vi These judgements consequently could not be contested on ethical grounds by patients or their family members. Questions of futility were resolved at the institutional level. Because the hospital had formal guidelines and because the establishment of futility was defined as a technical matter, ethics consultants refrained from assuming oversight in these cases. The typical recommendation reiterated hospital policy and deferred to medical judgement. 
Case 187 Recommendations: "Although the judgment of futility is in part a medical judgment beyond the scope of an ethics consult, such a consideration in this case is appropriate based on the medical facts presented, provided that the primary team concludes the condition is indeed terminal, and that no future beneficial effect of prior chemotherapy is foreseeable. Continue to work with the patient on goals of care as her condition evolves. This process has been effective to this point, and a decision to withhold further transfusions may be arrived at mutually."

The ultimate authority for determining whether a treatment was futile lay with the clinician, an understanding that was accepted and not challenged by ethics consultants.

\section{DISCUSSION}

\section{Defining the Problem}

Consistent with other studies (Arnold and Silver 2003; DuVal et al. 2001), a minority of the ethics consultations at Southwest Hospital involved novel ethical questions, characterised by moral ambiguity for patients and clinicians. More common were disagreements or conflicts between clinicians and patients' or their family members, which, although they had moral weight, were not characterised by a lack of ethical clarity for either party. How these cases were framed by the clinicians requesting consultation, and by the ethics consultants involved, often focused on one of two questions: Whether a patient was competent to decline a treatment or intervention (in cases where clinicians wanted to provide a treatment a patient was refusing) OR whether a treatment would be "futile" (in cases where patients or family members desired a treatment that clinicians didn't want to provide). Numerous studies on the types of cases ethics consultants see mirror our findings that end-of-life issues and disagreements about level of care were most common (DuVal et al. 2001; Shuman et al. 2013; Swetz et al. 2007; Tapper et al. 2010). Of note, we found that framing consultations around questions of futility and patient capacity significantly shaped the evidence and expertise that was drawn upon to answer them.

\section{Resolving Disagreements and Reinforcing Physician Authority}

Many of the strategies offered by ethics consultation to resolve cases did not often explicitly draw on expertise in ethics or philosophy but instead focused on resolving clinical ambiguities, 
facilitating better communication, reaching consensus, and ultimately, focusing on clinical judgements regarding the decision-making capacity of patients or the futility of treatment(s). When problems were brought to the ethics consultant, the first response of the consultant was to examine the care process and issues of communication. For example, the recommendations of ethics consultants often delineated the order in which the clinical team should approach making treatment decisions: first, establish the relevant clinical details, then determine who the appropriate decision-maker is, and finally, clearly communicate the patient's diagnosis and the options for treatment. Some scholars have described this process and communication work as a form of "institutional social work" (De Vries and Conrad 1998). Others have also noted the roles of ethicists in resolving communication problems; previous research points to lapses in communication as a major contributor to requests for ethics consultations (Shuman and colleagues 2013) and finds that facilitating communication is key to resolving the bulk of ethics consultations (Tapper et al. 2010).

Why then are ethics committees made up of clinicians rather than medical social workers? Treating a problem in communication as an ethical problem offers the veneer of ethics to an organisational problem; ethical problems are complex and require clinical expertise and professional wisdom. Directing communication problems to an ethics committee rather than a social worker meets an institutional need to protect limited physician time by off-loading timeconsuming conversations about emotionally fraught decisions while allowing these problems to remain in the medical domain.

The process and communication recommendations that typified ethics consultation often reinforced the perspectives and preferences of clinicians. Similarly, in cases where disagreements persisted, referral to clinical judgements - rendered in the case or baked into hospital policies - often resulted in recommendations that are aligned with clinicians' preferences. This reinforcing of physician authority was, in part, an outcome of the clinical orientation and organisational aspects of ethics consultation.

\section{Communication Strategies}

Consultant strategies designed to improve communication mirror strategies used to increase the likelihood that patients or their decision makers will elicit particular values or assent to the treatment preferences of clinicians (Anspach, 1997; Hall et al., 2012; Livne, 2019; Zussman, 
1997). For example, when patients or their family members had been presented with an alternate treatment option that the current clinical team or physician felt was inappropriate, ethics consultants often recommended that staff communicate with each other prior to presenting options to the patient or their family members. The effort to present a "united front" and show consensus around appropriate treatment may have suggested that the clinical picture was not ambiguous when there was still uncertainty among some team members (Anspach 1997). Similarly, discussions that allowed patients to express overarching goals or values but that framed specific treatment decisions as technical judgements within the purview of the medical team may have also served to limit the patient's or family's participation in decision-making (Livne 2019; Zussman 1992).

Finally, the use of palliative care specialists as "expert communicators" may have directed conversations towards specific treatment outcomes. At Southwest Hospital, 77\% of cases identified by ethics consultants as end-of-life or futility cases were instances in which patients wanted more treatment and clinicians favored less treatment. Livne (2019) finds that the hospice and palliative care fields believe that most patients would have better deaths if they received less aggressive intervention at the end of life. Palliative care teams at Southwest (and elsewhere) were thus well situated to engage in difficult conversations about end of life preferences and to guide conversations toward specific treatment ends, such as the limiting or withdrawal of treatments, that were felt to be in the best interests of patients and the hospital.

Our findings similarly support the premise that the involvement of palliative care frequently was not expected to be outcome neutral. As evident in the excerpts above, ethics consultants described palliative care as useful in having patients or their surrogates identify more appropriate goals of care and in transitioning them away from aggressive interventions physicians felt were inappropriate. While not always the case, the involvement of palliative care was often expected to result in goals associated with comfort care and the eventual withdrawal of aggressive interventions, and which were overwhelmingly in line with how clinicians wanted to proceed in these cases.

The Clinicians' Perspective

The foregrounding of a clinical perspective may also reflect how ethics consultation is requested. Ethics consultation requests at Southwest Hospital were overwhelmingly prompted by requests 
from clinical staff and not from patients or their surrogates, a finding consistent with other studies of ethics consultation (Tapper 2010; Shuman et al 2013; Voigt et al 2015). This could be the result, in part, of hospital staff being more aware of the availability of ethics consultation, more comfortable requesting these services, and better informed on what an ethics consult can accomplish. Regardless, because ethics consultations were requested primarily by the treating team or physician, the conflict or disagreement was most often framed as a question that clinicians themselves are equipped to answer, i.e., decision-making capacity or futility (Churchill 1999). Ethies consultants similarly considered the primary issue in the majority of "disagreement" cases as a decision-making capacity, futility, or end-of-life, issue. Additionally, the written recommendations produced by ethics consultants were directed at clinicians and became part of the medical record. Organisational aspects of ethics consultation, such as how they were most commonly called upon (by clinicians), guided the initial framing of the problem (by clinicians), and the way recommendations were recorded (for clinicians) shaped how consultants presented their advice. As such, both the initial and final presentation of the case were developed from the clinicians' perspective, which often reinforced a focus on technical judgements, made by clinicians.

There were other organisational aspects of ethics consultation which increased the likelihood that consultants would view cases from the clinicians' perspective. While ethics consultants may have been "strangers" at the bedside of patients, they were overwhelmingly colleagues of the clinicians involved, and this likely could not help but impact their ability to act as impartial outsiders (Churchill 1999; De Vries and Conrad 1998; White et al. 2018). At Southwest Hospital, most ethics consultants were clinicians themselves - during the study period, $76 \%$ of active committee members were clinicians of some kind ( $42 \%$ physicians, $12 \%$ medical students, and $22 \%$ other clinicians ${ }^{\mathrm{vi}}$ ). While only five consultations were performed without a physician member of the committee, 89 were performed without a non-clinician member ${ }^{\text {vii }}$ (either by a single clinician or team of individuals without a non-clinician member). Apart from their role as ethics consultants, most committee members were clinicians and peers to those requesting consultation. Indeed, the ethics committee was explicit in stating that ethics consultants should not challenge the clinical "facts" presented by the physicians involved. This produced a situation in which the opinions and facts presented by patients or their surrogates were more easily challenged than those presented by clinicians. 
Additionally, because they were socialised as clinicians and experienced in clinical care, ethics consultants were more likely to share cultural attitudes about appropriate end-of-life treatment with other clinicians. Although public opinion surveys and surveys of physicians show that the majority of both groups prefer less aggressive treatment at the end of life, recent evidence suggests that an increasing minority of the public prefers that "everything be done," doubling since 1990 (Pew Research Center 2013), and that there are substantial differences in these attitudes by SES and race (Barnato et al. 2009; Pew Research Center 2013). Given that clinician perspectives were more likely to be seen as evidence-based and were more likely to align with a consultant's own views about appropriate end-of-life care, patients and their families who disagreed with clinicians often had to resist multiple efforts to persuade them to assent to clinician's perspectives. Other research has found that the use of ethics consultation was associated with lower levels of intervention (Schneiderman et al. 2003) and resulted in treatment outcomes in line with the treating team's original preferences in $85 \%$ of cases (Voigt et al. 2015). The resolutions recommended by ethics consultants at Southwest Hospital suggest similar patterns, again suggesting that clinical perspectives took precedence.

\section{Patient vs. Physician Autonomy}

As evidenced above, many ethics consults at Southwest Hospital focused on key clinical judgements, such as whether a patient has decision-making capacity or whether a treatment should be considered futile, and these judgements provided the necessary evidence for deciding what was ethically appropriate. Descriptions of the limits of patient autonomy with respect to decision-making capacity and requests for treatment at the end-of-life were particularly salient in cases where other strategies could not produce consensus. By defining clinical judgement as most important in determining appropriate treatment, patient autonomy - sometimes regarded as the "first among equals" of the four principles of American bioethics (Gillon 2003) - was often portrayed as in conflict with doing what is clinically best for patients.

Some have questioned whether respecting patient autonomy and patient-centered care has actually improved medical outcomes (Lee and Lin 2010). Bosk (1992) and Kaufman (2015), in different contexts, suggest that by presenting patients with all possible treatment choices, clinicians may be abandoning decision-making onto those less equipped to comprehend the implications of those choices. Brody (1992) critiques the "patient autonomy" model of clinical 
ethics, designed to combat physician paternalism, suggesting it ultimately ignores the role of medical ethics in training virtuous physicians. Brody suggests that physicians will always have power in the medical encounter and that ethics ought not to seek to reduce this power but instead to equip physicians with the ability to use power responsibly. These arguments suggest that clinical judgements are the primary framework for defining and resolving the ethical questions that come to the attention of ethics committees. Similarly, we found that in ethicists' acknowledgements of patient autonomy and the limits of physician authority, they often made justifications for reinforcing that authority and prioritising technical expertise. However, one recent study found that paternalistic decision-making (and prioritising technical expertise) when clinicians, patients, and their families disagree had far less support among the lay public than among clinicians, highlighting how ideas of ethical decision-making may differ between clinicians and those they treat (Bailoor et al. 2018).

\section{CONCLUSION}

Our analysis reveals two important aspects of the role of clinical ethicists in medical decisionmaking in the twenty-first century. First, ethical questions brought to ethics committees are often reframed as teehnical judgements that rely on the technical expertise of clinicians. Initially seen or defined as requiring ethical expertise, issues become 'remedicalised' and refocused on clinical judgements (Conrad 2007). Second, while ethics consultants may be seen as "strangers" at the bedside, they do not often pose significant challenges to physician authority. Contrary to the notion that bioethicists would (or should) promote an "independent voice" in medical decision making (De Vries and Conrad 1998), give voice to the moral perspectives of "ordinary people" (Churchill 1999), and challenge medical authority (Rosenberg 1999), ethics consultants most often put key decisions back in the hands of clinicians (Brody 1992; De Vries, Dingwall, and Orfali 2009). Bosk has asserted that "bioethicists' claims that they have provided patients a greater voice in determining their own affairs" are not incorrect, but rather that the extent to which they have accomplished this is not "as dramatic as their promoters would have us believe" (1999: 64). Our analysis supports his claim. In many cases the resolution of the problems brought to ethics committees is found in assent to clinicians' judgements and treatment preferences. 
This characteristic of ethics consults says nothing about the value of these consults. Although there is a paucity of research on the topic, studies that have been done show that ethics consultation services are often well received by patients and clinicians (DuVal et al. 2004; Schneiderman et al. 2003), although Cohn and colleagues (2007) and Orr and colleagues (1996) found that patient satisfaction is generally lower than clinician satisfaction. More studies of this type are necessary to fully understand the process, place, and effect of hospital ethics consults.

Our study has limitations that constrain the generalisability of our findings. First, the analysis explores clinical ethics consultation at a single institution, and literature suggests the practice of ethics consultation is done differently at different institutions (Fox et al. 2007). However, as a large tertiary care institution, Southwest Hospital does have a particularly busy ethics consultation service (Fox et al. 2007), which offered the opportunity to examine a significant number of consultations over a nearly four-and-a-half-year period. Furthermore, our review of the literature on ethics consultation suggests that the way ethics consultation was done at Southwest Hospital was in keeping with the competencies defined by the American Society for Bioethics and Humanities (ASBH Core Competencies Update Task Force 2011). Finally, the procedures in place at Southwest Hospital for assessing capacity and their formal futility policy are common to many other institutions (Rosoff 2013; Truog and Mitchell 2006), although it is possible the way these policies are deployed still varies.

Another limitation is that we relied on the written record produced by the ethics consultant(s) and the committee discussion about each case. We did not observe ethics consultants performing ethics consultation, and therefore our analysis is based on descriptions of the consultation process, written recommendations, and written discussions about how to proceed. Consultation records certainly varied in length, and it is possible that additional recommendations were given verbally and not included in the written record. Others have noted (Anspach 1997; Zussman 1992) how medical records may gloss over processes of decision-making and/or overemphasise patients' roles in decision-making. However, the written records of the ethics committee differed from traditional notes in the medical record in meaningful ways. First, case presentations generally sought to capture the conflict or disagreement that prompted the consultation rather than simply the resolution or decision reached. Second, the consultants could, and did, pose questions to their fellow committee members, and vice versa, in these records. As Zussman (1992) found the production of DNR orders reflected the audience of these records (in contrast to 
other medical orders and chart notation), the documentation practices of ethics consultants at Southwest Hospital similarly reflect professionalisation trends in clinical ethics that demand records detailed enough for outside review. In that way, these records were more illustrative of the kinds of thinking and framing ethics consultants deployed than traditional medical record notation.

The analysis of the written record produced during ethics consultation is used to evaluate the quality of ethics consultation and is regarded as a reliable record of what has occurred in the consultation and the advice provided (Pearlman et al. 2016). While we acknowledge narratives of processes in these records may be circumscribed, we contend that for our purposes, the written record offered substantial leverage in examining the types of cases that present for ethics consultation as well as the strategies and arguments used by ethics consultants to resolve conflicts.

Despite these limitations, our findings provide meaningful insight into the performance of clinical ethics consultation and its implications for physician authority. Our analysis reveals that in many instances clinical ethicists seek to resolve conflicts in patient care with process and communication strategies targeted at producing consensus. Further, in many cases, ethics consults prioritise technical, clinical judgements and thus work to produce agreement with a clinician's preferred treatment plans, subtly reinforcing clinical authority in disputes.

Those who have detailed the history of medical ethics and the rise of bioethics highlight that discussions of medical and science ethics transitioned from a conversation among insiders (physicians and scientists) to one that included outsiders, some of whom came to be known as bioethicists (Evans 2012; Rothman 1991; White et al. 2018). The substantial institutionalisation of clinical ethics over the past few decades suggests that bioethicists could play a sustained and meaningful role in medical decision making. However, in the area of clinical ethics, where the jurisdiction of bioethics is least contested (Evans 2012), a closer examination suggests that clinical ethicists are likely to be clinicians themselves, and that clinical considerations are often the ultimate authority in defining what is, and is not, determined to be ethical. 


\section{ACKNOWLEDGMENTS}

We are grateful for the feedback provided by the Medicine, Aging, Science, and Health workshop and the Social Movements workshop at the University of Michigan, and specifically, Renee Anspach, Sarah Burgard, Roi Livne, and Justin Naifeh for their helpful comments and suggestions on earlier drafts of this manuscript. We also received useful advice from colleagues at the Center for Bioethics and Social Sciences and Medicine. The first author was supported in part by an NIA training grant to the Population Studies Center at the University of Michigan (T32AG000221).

Address for correspondence: Katrina Hauschildt, 500 South State St. $\quad$ LSA Building, Ste. 3115, Ann Arbor, MI 48109. E-mail: kehaus@umich.edu

\section{ENDNOTES}

${ }^{\mathrm{i}}$ Southwest Hospital is a pseudonym.

ii Because a web-based data management software was used for detailed coding, we made sure any patient identifying information was removed before uploading the consultation records to Dedoose.

iii Patient's race/ethnicity was very rarely recorded in the consultations records $(n=9 / 156)$.

iv DPOA [Durable Power of Attorney] paperwork refers to a document a patient can complete which names someone else to make health care decisions for that patient if/when they are not able to make decisions themselves.

v Patients may be deemed to lack decision-making capacity for some but not all decisions or for a period; this is a clinical judgement and does not require a court's involvement. When a patient lacks capacity, a surrogate decision-maker is identified (i.e., the patient's closest family member). Competency is technically a legal determination but is based on clinical judgement. Patients deemed to lack competency must have guardians formally appointed. 
vi This particular phrase is used in numerous consults where a question of futility is raised.

vii Non-physician clinicians include 2 physician's assistants, 3 social workers, 2 nurses, 2 nurse practitioners, 1 laboratory scientist, and 1 genetic counselor.

viii Non-clinicians include 4 administrators, 4 lawyers, 2 chaplains, 2 community members, and 1 philosopher.

Table 1. Consultation Descriptives

\begin{tabular}{|c|c|c|c|}
\hline$\%$ & isults & \# of Consultants & \% of Consults \\
\hline$\overline{\mathrm{Mal}}$ & $43 \%$ & 1 & $44 \%$ \\
\hline Female & 57 & 2 & 40 \\
\hline & & $3-4$ & 16 \\
\hline \multicolumn{4}{|l|}{ Age } \\
\hline $18-40$ & $23 \%$ & Length of Consult & \\
\hline 41-60 & 27 & $30 \mathrm{~min}-1.5 \mathrm{hrs}$. & $25 \%$ \\
\hline $61-75$ & 28 & $2-3.5 \mathrm{hrs}$ & 38 \\
\hline $76+$ & 16 & $4+$ hrs. & 11 \\
\hline Not Recorded & 6 & Not Recorded & 25 \\
\hline
\end{tabular}

Table 2. Summary of Types of Cases

\begin{tabular}{lr}
\hline \multicolumn{1}{c}{ Case Types } & \% of Consults \\
\hline Ethical Dilemmas A & $15 \%$ \\
Identifying Surrogate Decision Maker & 15 \\
Disagreements Amongst Clinicians & 3 \\
Disagreements Amongst Patient & 4 \\
and/or Patient's Surrogates & \\
Disagreements Between Clinicians & 63 \\
and Patients or their Surrogates B C & 42 \\
\multicolumn{2}{c}{ Patients/Surrogates want more treatment } \\
$\quad$ Clinicians want more treatment
\end{tabular}


${ }^{A}$ Cases characterised by novel ethical questions in which the moral choice was unclear to the parties involved

${ }^{B}$ Cases characterised by disagreement between the legal decision-maker and clinicians are included in this category

${ }^{C}$ Latter categories represent subsets of this type

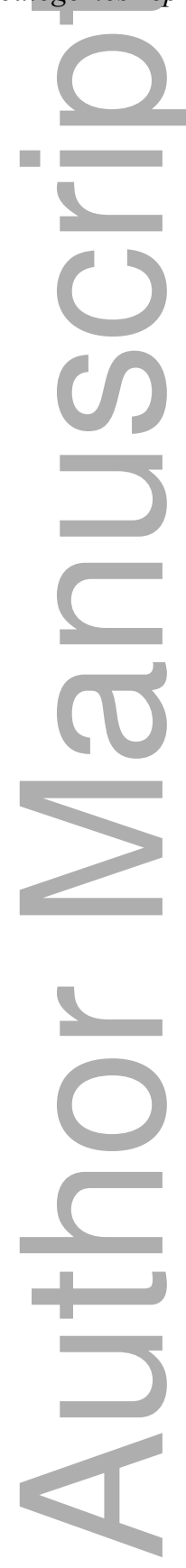

This article is protected by copyright. All rights reserved 
Appendix A. Examples of Case Types

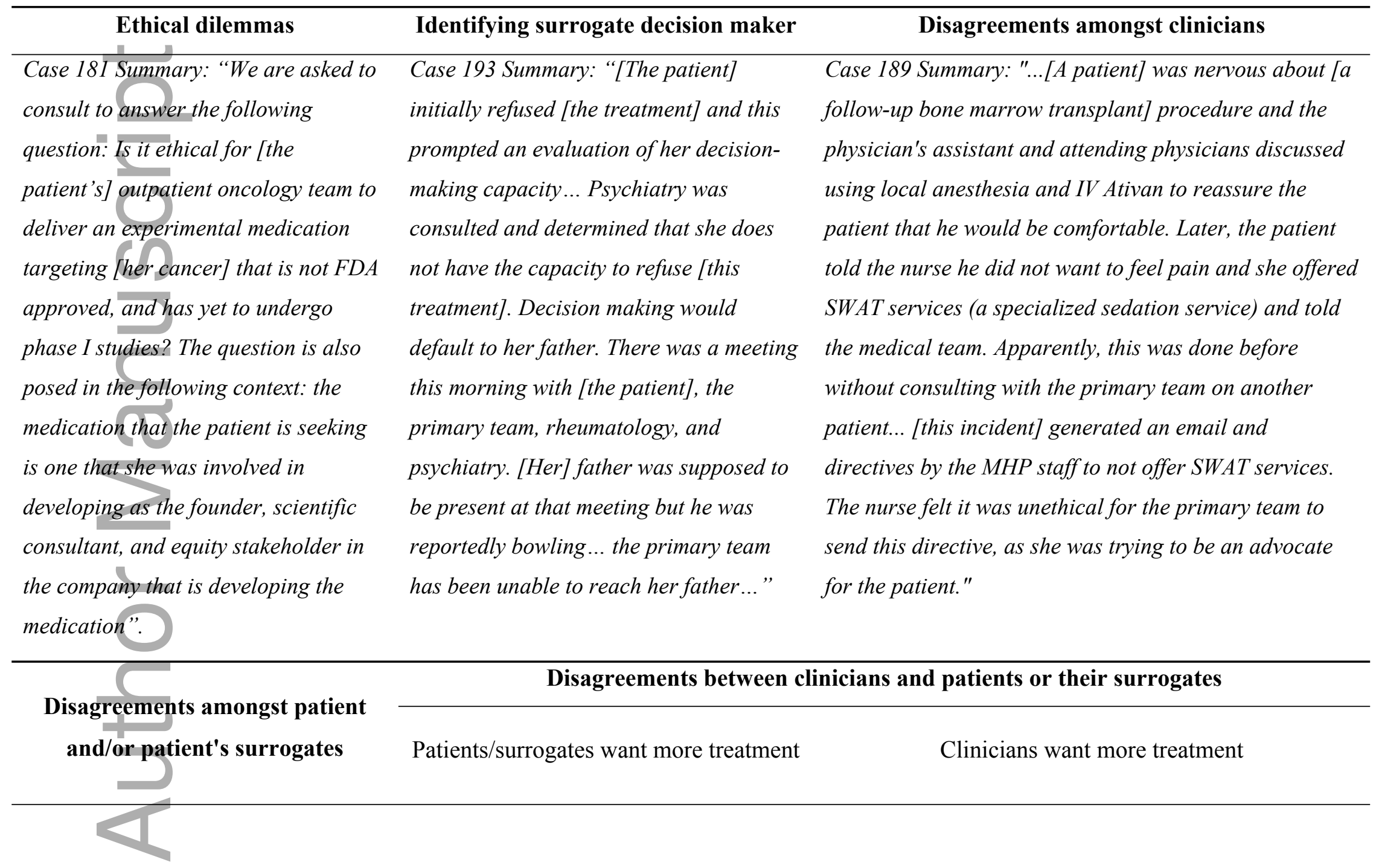

This article is protected by copyright. All rights reserved 
Case 185 Summary: "[The patient] has chronic pain and has been almost continuously hospitalized over the past two years. He decided one year ago that he wanted to discontinue the ventilator and die... while psychiatry believes he has decision-making capacity, he recently changed his mind on the day that he was supposed to die. His family gathered for this event, including his wife and mother (who are opposed to his decision). His wife cried and told him that it was against their religion and he acquiesced and became full code again."

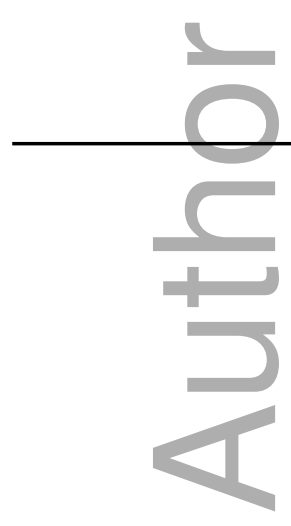

Case 211 Summary: "[The patient] has a history of metastatic cervical cancer that has not responded to [treatment]... The oncologists feel that there are no further options for treatment and have recommended palliative care and discharge to hospice. Her family wants "everything done" and views leaving the hospital as giving up... Ethics was consulted by the [department] fellow because of concerns for futility."
Case 129 Summary: "The patient was admitted with a brain hemorrhage due to a recently diagnosed intracranial aneurysm. He remains intubated and sedated. His neurosurgeon recommends proceeding with endovascular repair of the aneurysm and quotes a roughly $70 \%$ likelihood of a good neurologic outcome. If untreated, the patient has a very high chance for a neurologically devastating or fatal event within the coming months. The patient's wife reports that he does not like going to doctors and has always avoided medicine and medical interventions. She does not think he would want to proceed with any invasive procedures... She has requested foregoing additional procedures (including repair of the aneurysm) and moving toward extubation. Ethics has been consulted given treatment refusal by a surrogate decision-maker in opposition with medical recommendations."

This article is protected by copyright. All rights reserved 


\section{WORKS CITED}

American Society for Bioethics and Humanities' Core Competencies Update Task Force (2011) Core competencies for health care ethics consultation: The report of the American Society for Bioethics and Humanities. 2nd edition. Genview, IL: American Society for Bioethics and Humanities.

Anspach, R.R. (1997) Deciding who lives: Fateful choices in the intensive-care nursery. Univ of California Press.

Arnold, R.M. and Silver, M.W. (2003) Techniques for Training Ethics Consultants: Why Traditional Classroom Methods are not Enough. In Aulisio, M.P., Arnold, R.M., and Youngner, S.J. (eds.) Ethics Consultation: From Theory to Practice. Baltimore, MD: Johns Hopkins University Press. pp. 70-87.

Bailoor, K., Valley, T., Perumalswami, C., Shuman, A.G., et al. (2018) How acceptable is paternalism? A survey-based study of clinician and nonclinician opinions on paternalistic decision making, AJOB Empir Bioeth. 9, 2, 91-8.

Barnato, A.E., Anthony, D.L., Skinner, J., Gallagher, P.M., et al. (2009) Racial and ethnic differences in preferences for end-of-life treatment, Journal of General Internal Medicine. 24, 6, 695-701.

Bosk, C.L. (1999) Professional Ethicist Available: Logical, Secular, Friendly, Daedalus. 128, 4, $47-68$.

Bosk, C.L.(2003) Forgive and Remember: Managing Medical Failure, Second Edition. Chicago: University of Chicago.

Bosk, C.L. (2008) What Would You Do? Juggling Bioethics and Ethnography. Chicago: University of Chicago.

Brody, H. (1992) The Healer's Power. New Haven, CT: Yale University Press.

Byhoff, E., Harris, J.A., Langa, K.M. and Iwashyna, T.J. (2016) Racial and Ethnic Differences in 
End-of-Life Medicare Expenditures, Journal of the American Geriatrics Society. 64, 9, 1789-97.

Chambliss, D.F. (1996) Beyond Caring: Hospitals, Nurses, and the Social Organization of Ethics. Chicago: University of Chicago Press.

Churchill, L.R. (1999) Are We Professionals? A Critical Look at the Social Role of Bioethicists, Daedalus. 128, 4, 253-74.

Cohn, F., Goodman-Crews, P., Rudman, W., Schneiderman, L.J., et al. (2007) Proactive ethics consultation in the ICU: A comparison of value perceived by healthcare professionals and recipients, Journal of Clinical Ethics. 18, 2, 140-7.

Conrad, P. (2007) The Medicalization of Society: On the Transformation of Human Conditions into Treatable Disorders. Baltimore, MD: Johns Hopkins University Press.

Conrad, P. and Leiter, V. (2004) Medicalization, Markets and Consumers, Journal of Health and Social Behavior. 45, S, 158-76.

DuVal, G., Clarridge, B., Gensler, G. and Danis, M. (2004) A National Survey of U.S. Internists' Experience with Ethical Dilemmas and Ethics Consultation, Journal of general internal medicine. 19,251-8.

DuVal, G., Sartorius, L., Clarridge, B., Gensler, G., et al. (2001) What triggers requests for ethics consultations?, Journal of Medical Ethics. 27, Suppl 1, i24-9.

Emerson, R.M., Fretz, R.I. and Shaw, L.L. (2011) Writing Ethnographic Fieldnotes. Chicago: University of Chicago Press.

Evans, J. (2012) The History and Future of Bioethics: A Sociological View. New York: Oxford University Press.

Fins, J.J., Kodish, E., Cohn, F., Danis, M., et al. (2016) A pilot evaluation of portfolios for quality attestation of clinical ethics consultants, The American Journal of Bioethics. 16, 3, $15-24$.

This article is protected by copyright. All rights reserved 
Fox, E., Myers, S. and Pearlman, R.A. (2007) Ethics consultation in United States hospitals: a national survey, The American Journal of Bioethics. 7, 2, 13-25.

Fox, R.C. and Swazey, J.P. (2008) Observing Bioethics. New York, NY: Oxford University Press.

Freidson, E. (1988) Profession of Medicine: A Study of the Sociology of Applied Knowledge. Chicago: University of Chicago Press.

Gillon, R. (2003) Ethics needs principles - four can encompass the rest - and respect for autonomy should be "first among equals", Journal of Medical Ethics. 29,307-12.

Hall, D.E., Prochazka, A. V and Fink, A.S. (2012) Informed consent for clinical treatment, Canadian Medical Association Journal. 184, 5, 533-8.

Joint Commission on Accreditation of Healthcare Organization (2007) Comprehensive Accreditation Manual for Hospitals: The Official Handbook. Joint Commission Resources.

Jonsen, A.R. (1998) The Birth of Bioethics. 1st edition. New York, NY: Oxford University Press.

Kaufman, S.R. (2015) Ordinary Medicine: Extraordinary Treatments, Longer Lives, and Where to Draw the Line. Durham, NC: Duke University Press.

Keirns, C., Fetters, M. and De Vries, R. (2009) Bioethics and Medical Education. In Brosnan, C. and Turner, B. (eds.) Handbook of the Sociology of Medical Education. London: Routledge. pp. 174-90.

Kohlen, H. (2011) Shifting responsibilities in the medical field: US-American bioethics and its move into the hospital setting. In Braun, K. (ed.) Between Self-Determination and Social Technology. Medicine, Biopolitics and the New Techniques of Procedural Management. Bielefeld, Germany: Transcript-Verlag. pp. 127-57.

Lee, Y.-Y. and Lin, J.L. (2010) Do patient autonomy preferences matter? Linking patientcentered care to patient-physician relationships and health outcomes, Social science \& medicine. 71, 10, 1811-8. 
Livne, R. (2014) Economies of Dying The Moralization of Economic Scarcity in US Hospice Care, American Sociological Review. 79, 5, 888-911.

Livne, R. (2019) Values at the End of Life: The Logic of Palliative Care. Cambridge, MA: Harvard University Press.

McKinlay,J.B. and Marceau, L.D. (2013) The End of The Golden Age of Doctoring. In Conrad, P. and Leiter, V. (eds.) The Sociology of Health and Illness: Critical Perspectives. 9th edition. New York, NY: Worth Publishers. pp. 234-60.

Orfali, K. (2018) Getting the Story Straight: Clinical Ethics as a Distinctive Field, The American Journal of Bioethics. 18, 6, 62-4.

Orr, R.D., Morton, K.R., DeLeon, D.M. and Fals, J.C. (1996) Evaluation of an Ethics Consultation Service: Patient and Family Perspective, American Journal of Medicine. $101,135-42$.

Pearlman, R.A., Foglia, M.B., Fox, E., Cohen, J.H., et al. (2016) Ethics consultation quality assessment tool: A novel method for assessing the quality of ethics case consultations based on written records, The American Journal of Bioethics. 16, 3, 3-14.

Pew Research Center (2013) Views on End-of-Life Medical Treatments. [Online].

Rosoff, P. (2013) Institutional Futility Policies Are Inherently Unfair, HEC Forum. 25, 3, 191209.

Rothman, D.J. (1991) Strangers at the bedside: a history of how law and bioethics transformed medical decision making. Basic Books.

Schneiderman, L.J., Gilmer, T., Teetzel, H.D., Dugan, D.O., et al. (2003) Effect of Ethics Consultations on Nonbeneficial Life-Sustaining Treatments in the Intensive Care Setting, JAMA. 290, 9, 1166-72.

Shuman, a G., Montas, S.M., Barnosky, a R., Smith, L.B., et al. (2013) Clinical ethics consultation in oncology, Journal of Oncology Practice. 9, 5, 240-5. 
Starr, P. (1982) The Social Transformation of American Medicine. Basic Books.

Swetz, K.M., Crowley, M.E., Hook, C. and Mueller, P.S. (2007) Report of 255 clinical ethics consultations and review of the literature., Mayo Clinic proceedings. Mayo Clinic. 82, 6, 686-91.

Tapper, E.B., Vereler, C.J., Cruze, D. and Sexson, W. (2010) Ethics Consultation at a Large Urban Public Teaching Hospital, Mayo Clinic Proceedings. 85, 5, 433-8.

Tarzian, A.J. and ASBH Core Competencies Update Task Force (2013) Health Care Ethics Consultation: An Update on Core Competencies and Emerging Standards from the American Society for Bioethics and Humanities' Core Competencies Update Task Force, The American Journal of Bioethics. 13, 2, 3-13.

Tham, S.J. and Letendre, M.C. (2014) Health Care Decision Making: Cross- Cultural Analysis of the Shift from the Autonomous to the Relational Self, The New Bioethics. 20, 2, 174-85.

Timmermans, S. and Oh, H. (2010) The Continued Social Transformation of the Medical Profession, Journal of Health and Social Behavior. 51, S, 94-106.

Truog, R.D. and Mitchell, C. (2006) Futility-From Hospital Policies to State Laws, American Journal of Bioethics. 6, 5, 19-21.

Voigt, L.P., Rajendram, P., Shuman, A.G., Kamat, S., et al. (2015) Characteristics and Outcomes of Ethics Consultations in an Oncologic Intensive Care Unit, Journal of Intensive Care Medicine. 30, 7, 436-42.

De Vries, R. (2017) Regarding Bioethics: A Sociology of Morality, Perspectives in Biology and Medicine. 60, 1, 74-92.

De Vries, R. and Conrad, P. (1998) Why bioethics needs sociology. In De Vries, R. and Subedi, J. (eds.) Bioethics and Society. New Jersey: Prentice Hall. pp. 233-57.

De Vries, R., Dingwall, R. and Orfali, K. (2009) The moral organization of the professions: Bioethics in the United States and France., Current Sociology. 57, 4, 555-79. 
White, B.D., Shelton, W.N. and Rivais, C.J. (2018) Were the "Pioneer" Clinical Ethics Consultants "Outsiders"? For Them, Was "Critical Distance" That Critical?, American Journal of Bioethics. 18, 6, 34-44.

Zussman, R. (1992) Intensive care: Medical ethics and the medical profession. University of Chicago Press.

Zussman, R. (1997) Sociological Perspectives on Medical Ethics and Decision-Making, Annual Review of Sociology. 23,171-89.

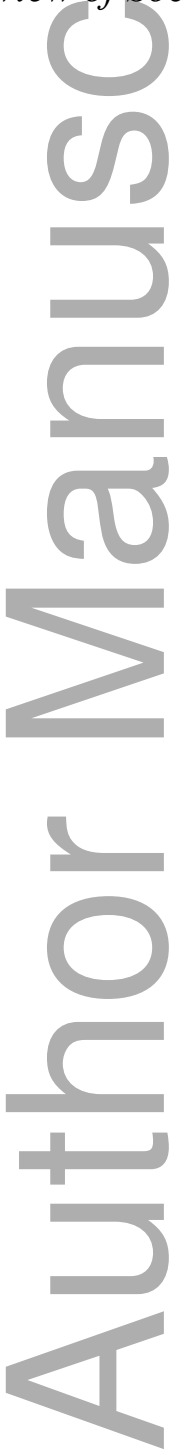

This article is protected by copyright. All rights reserved 